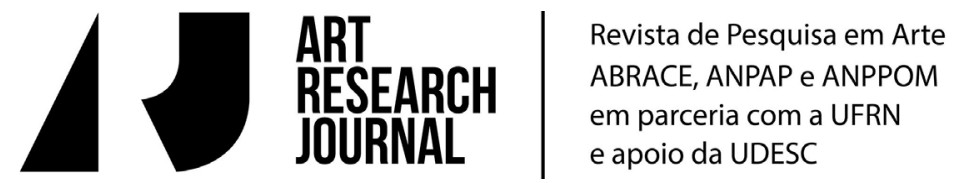

\section{Teatro como campo expandido: a imagem em Gilles Deleuze e Hans-Thies Lehmann}

\author{
Ricardo Nascimento Fabbrini \\ Universidade de São Paulo, Brasil
}

A crítica de Gilles Deleuze, ao longo de sua trajetória, à função de representação da imagem pela consciência, bem como sua substituição pela ideia de imagem enquanto "um efeito de matéria" ou "como individuação", tem sido reconstituída, cuidadosamente, por Anne Sauvagnargues. Na reconstrução da passagem da imagem do pensamento à imagem-individuação, a autora analisa, em uma primeira etapa, Nietzsche e a filosofia, de 1962, e Proust e os signos, de 1964, de Deleuze. Nestas obras, teríamos a substituição da "imagem representativa do pensamento", entendida como "um modo de pensamento voltado para a transcendência da verdade", por uma "nova imagem do pensamento" (Sauvagnargues, 2015, s.p.). ${ }^{1}$ Seria, contudo, em Diferença e Repetição, de 1968, que Deleuze teria desenvolvido esta crítica aos "ardis da representação" e da "diferença ontológica do modelo e da cópia", haja vista que "já se pode afirmar, nesta obra, que a imagem-individuação está bem presente posto que a filosofia da diferença, aqui se ampara em uma filosofia da individuação em devir, não centrada sobre um indivíduo substancial, forma constituída, alma antropológica" (idem, s.p.). Essa imagem seria especificada, por fim, por Deleuze, nos livros Cinema 1, a imagem-movimento, de 1983, e Cinema 2, a imagem-tempo, de 1985, a partir de uma problemática bergsoniana, como "individuação sensório-motora", como veremos, em nossa caracterização do teatro expandido.

\footnotetext{
${ }^{1}$ Anne Sauvagnargues (École Normale Supérieure: Lettres et Sciences humaines - Lyon) apresentou o ensaio publicado originalmente em 2013, "Écologie des images et machine d'art", no Colóquio FFLCH-USP - Université Paris Ouest; Nanterre La défense, organizado pela Comissão de Cooperação Internacional da Faculdade de Filosofia, Letras e Ciências Humanas da Universidade de São Paulo (Ccint- FFLCH-USP) em 27/02/2015 (mimeo, s.p.).
} 
Deste percurso teria resultado, ainda segundo Sauvagnargues (2006, p. 162), a ideia deleuzeana de uma "comunidade das artes", na qual cada uma delas estaria voltada para "a captura de forças, para o agenciamento de novas forças insensíveis em novos materiais, como se verificaria não apenas no cinema, mas também na literatura (em Crítica e clínica, de 1997), na pintura (em Francis Bacon, lógica da sensação, de 1981) e mesmo, na música. Essa ideia de uma comunidade das artes, constituída a partir da noção de imagem-individuação será, no entanto, aqui estendida ao teatro, de modo que tomaremos essa ideia de comunidade como "teatro cinematográfico", "teatro com mídias", "teatro intermídia", "teatro pansemiótico", ou "teatro da dramaturgia visual", nas expressões de diferentes autores: um teatro, enfim, marcado pela incorporação de registros de mídias como fotografia, holografia, cinema, ou vídeo, daí resultando diferentes regimes de imagens. Esse teatro como campo expandido - sabendo-se, evidentemente, que o teatro desde os gregos sempre incorporou novos meios técnicos - remete de imediato à noção de obra de arte total (Gesamtkunswerk) do romantismo, no século 19, e ao projeto das vanguardas artísticas do início do século 20. Sendo assim, antes de caracterizar esse teatro como comunidade das artes, concebida a partir da noção deleuzeana de imagem individuação, convém inscrevê-lo no arco mais amplo das vanguardas artísticas.

Recorde-se, em linhas gerais, que as vanguardas artísticas, de extração romântica, também visavam estetizar o real, ou seja, embaralhar arte e vida. Foram, no entanto, movimentos artísticos de sinais contrários, haja vista que assumiram estratégias opostas: por um lado, as vanguardas positivas, de raízes construtivas, que, apostando nos poderes da racionalidade técnico-científica, intentaram pela produção industrial de mercadorias, introduzir a arte, por intermédio do design, no cotidiano do dito homem comum; por outro lado, as vanguardas destrutivas, de raízes dadá-surreais, que criticando a aposta cega nos poderes supostamente libertários da racionalidade instrumental, buscavam liberar o mundo onírico, no interior de uma sociedade regida pelo valor de troca, própria à lógica do capital. Neste último caso, intentava-se na tradição do dandismo do século 19, fazer da própria vida, arte. Para esses artistas, dandys ou dadás, tratava-se de, reagindo ao sex-apeal do inorgânico (ao fetichismo da mercadoria), fazer com que irrompesse subitamente na vida, em meio à rotina cinzenta do dia a dia - como um 
estrondo - a poesia (ou mirabilia, como sonhavam os surrealistas).

Destaque-se, por fim, que se o projeto moderno tivesse cumprido seu intento de estetizar a vida, isso acarretaria, segundo o ideário vanguardista, o fim da arte enquanto forma autônoma. Acentue-se, nessa direção, que Piet Mondrian, por exemplo, vaticinava, nos anos 1920, que se o programa do neoplasticismo se efetivasse "não teríamos mais necessidade de pintura e escultura porque viveríamos, a partir de então, na arte realizada" (Mondrian, 2008, p. 171). Essa "convicção de Mondrian", como lembra Guy Brett, foi também determinante na constituição do imaginário de diversos artistas das vanguardas tardias, nos anos 1960 e 1970 (Brett, 2005, p. 56). Nesse estado de "síntese das artes", ou de "obra de arte total", ou melhor, no "estado de arte sem arte", como dizia de modo análogo Lygia Clark, nos anos 1960, "não haveria mais diferenças intrínsecas entre ser e criar, existir e produzir" (Clark, 1998, p. 188). Não apenas os objetos seriam, neste "estado estético", ao mesmo tempo, belos e úteis, como no homem vigoraria a plena harmonia entre sensibilidade e entendimento, ou, entre "impulso formal" e "impulso sensível", mediado pelo "impulso lúdico" (ou imaginação) nos termos ainda kantianos de Friedrich Schiller. Em outros termos: o programa vanguardista do século passado, de extração romântica, visava a "constituir uma nova espécie de ser" - o "homem pleno" - concedendo à "existência humana", sua "liberdade essencial" (Schiller, 1990, p. 83).

Não é possível, no entanto, identificar o "teatro como campo expandido", resultante da confluência de linguagens artísticas, como teatro e cinema, seja ao programa das vanguardas históricas dos anos 1910 ou 1920, como o dadaísmo ou futurismo, seja ao ideário contracultural das vanguardas tardias, como os happenings ou a body art, dos anos 1960 ou 1970; porque, como mostraram recentemente Nicolas Bourriaud e Hans Obrist, o artista "nos dias de hoje" não busca mais a "reconciliação entre arte e vida" na "forma utópica da obra de arte total", mas insere signos, pragmaticamente, no "cotidiano vivido", produzindo "alteridades possíveis" (Bourriaud, 2011, p. 168). Ou seja: o investimento da arte de vanguarda, tanto heroica quanto tardia, na "transformação do mundo", segundo "o esquema revolucionário" orientado por uma "utopia política", teria sido substituído, por um "realismo operatório", voltado para a uma "utopia cotidiana, flexível" (ou "heterotopia"), de "invenção do possível", da arte pós-vanguardista (idem). A noção de obra de arte total tomada, agora, em termos mais restritos porque limitados à "plataforma" 
ou "estação" entendida como territórios nos quais estariam gestando-se "laboratorialmente" novos modos de se habitar o mundo existente, distancia-se, assim, da ideia romântica e vanguardista de construção de uma sociedade radicalmente outra. Ou seja: é possível pensar a negatividade da arte, depois das vanguardas, a partir da confluência das linguagens artísticas, sem que se atribua à forma artística, ou à poética do gesto (dadá ou neodadá), poderes utópicos revolucionários. Pode-se, nesse quadro, conceber o teatro expandido como lugar privilegiado para o exame da possibilidade de "outra versão do virtual" (de uma "nova imagem")? O teatro como campo expandido, enquanto amálgama de mídias - como mostrou Hans-Thies Lehmann em Teatro pós-dramático - é composto de signos corporais e signos de luz. Não se supõe, aqui, evidentemente, um teatro multimídia como "máquina de imagens que efetua apenas uma reprodução da realidade"; como algo subsidiário, "de mero reforço do texto" (Lehmann, 2007, p. 368). Não se considera, portanto, este teatro como resultante "da adaptação do cinema ou vídeo ao teatro", atribuindo-se "à imagem eletrônica uma função ocasional de endosso da representação corrente", das imagens circulantes na televisão, na internet ou no cinema de entretenimento (idem, p. 382). De fato, na perspectiva de Jean Baudrillard cujo pensamento se mostra mais atual à medida que o tempo corre, como percebe Lehmann - teríamos, neste caso, uma encenação visual em sentido fraco, porque de reafirmação da imagem hegemônica na sociedade do espetáculo, a saber: de imagens planas (seja em HD, ou 3D); chapadas; lisas; superficiais; epidérmicas; peliculares; sem recuo; sem enigma; sem mistério; sem face oculta; sem outro lado; sem pregas; sem dobras; sem cimo; sem avesso. ${ }^{2}$ São imagens planas "já que nenhuma meta aparece na consciência como pano de fundo da imagem" - como quer Lehmann, corroborando o diagnóstico de Baudrillard -, "diferentemente do que acontece quando o olho permanece diante do corpo real", de modo que face àquelas imagens "nenhuma falta aparece" (idem, p. 401). Não haveria nessas imagens que circulam no "écran-plasma-total" (Baudrillard, 2005), qualquer "relevo, perspectiva, ou linha de fuga" que fizesse com que "o sistema formal da visão", "correndo o risco de perder-se", se investisse de pulsão, convertendo-se em "olhar" de um "sujeito desejante", no sentido de Jacques Lacan (1996).

\footnotetext{
${ }^{2}$ Nos termos utilizados por Jean Baudrillard, ao longo de sua copiosa ensaística, na caracterização do estatuto da imagem na "sociedade do simulacro".
} 
No teatro expandido, o avesso da tela-total, não haveria, assim, instrumentalização das mídias, como ocorre, muita vez, na aplicação das tecnologias midiáticas à encenação do teatro dramático baseada no texto e na representação; e não haveria, tampouco, uma espetacularização dessas tecnologias visando efeitos virtuosísticos como se evidencia no cinema blockbuster norte-americano. De toda maneira, destaque-se que na incorporação de mídias eletrônicas - relembrando-se como dizíamos que a assimilação de meios técnicos, como iluminação ou projeções, integraram a própria história da encenação teatral - há dois riscos a serem evitados pelo dramaturgo: a conversão do teatro a meio de comunicação (a documento); e sua redução à condição de espetáculo (ou evento cultural), na chave do "fascínio", no sentido de Baudrillard (1991), ou do "abuso estético", como quer Jean Galard (2012).

Destaque-se, antes de analisar os riscos de uma dada obra soçobrar na comunicação imediata, ou na espetacularização da cultura, o sentido atribuído, aqui, ao teatro da dramaturgia visual, ou "cine-poético", como também já foi denominado, não esquecendo, que, nesse teatro, o corpo do ator, em interação com a imagem eletrônica, também é, por sua vez, corpo de luz. Pode-se dizer, ainda, que esse teatro, assim visionado, é simplesmente um "teatro da imagem" se tomarmos o termo no sentido atribuído por Gilles Deleuze à "imagem-individuação", a partir de Henri Bergson, à qual nos referíamos. Porque a crítica que Deleuze desenvolveu aos ardis da representação e à diferença ontológica entre modelo e cópia opera eficazmente na interpretação do teatro expandido, haja vista que esse teatro se opõe à imagem-representação do teatro dramático, do cinema clássico, assim como à imagem simulacro do mundo mass-midiático. O teatro priorizado por Deleuze, vale reforçar, é aquele que modifica a matéria teatral; é a forma de teatro que cessa de ser representação, constituindo-se, assim, como "teatro da não representação", na linha de Antonin Artaud, Bob Wilson, Jerzy Grotowiski ou Living Theater (Deleuze, 2010). Essa noção de "imagem-individuação" de Gilles Deleuze, enquanto crítica à representação, como dizíamos acima, converteu-se nos livros sobre cinema, "Cinema 1, a imagem-movimento", de 1983, e "Cinema 2, a imagem-tempo", de 1985, em operador de discursos, que, aqui mobilizamos em nossa caracterização do "teatro expandido" (ou comunidade das artes). Partindo da problemática bergsoniana, a "imagem-individuação" é caracterizada, nestes livros, como "individuação sensó- 
rio-motora", como "centro sensível de indeterminação" que, "traçando perspectivas", desdobra-se como "feixe de percepções, de ações e de afecções subjetivas e materiais", nos termos de Deleuze (1985). É possível, assim, operando com a noção de "imagem-individuação", vincular o "teatro da não representação" a uma "filosofia não substancial", das singularidades (ou da "hecceidade"), na qual a imagem não seria mais tida como "reprodução passiva de algo externo", mas como "produção de uma diferença" (Deleuze; Guattari, 1997); ou ainda, como "agenciamento coletivo", ou como "efeito de matéria", nos termos partilhados por Deleuze (idem) e Jacques Rancière (2012).

A "imagem-individuação" constitui-se, em outros termos, como dualidade entre "uma individuação atual e uma subjetivação virtual"; em "metamorfose, ou em devir" (Deleuze, 1988). Esta imagem, estendendo o "arco sensório-motor", "captaria os devires em ato" como "nova experimentação", como quer Deleuze (idem). Em outros termos: o "teatro-cinema" pode ser o lugar para evidenciação de uma imagem não substancializada, posto que a "imagem-individuação" é "a própria imagem e seu modelo", de modo que ela pode efetuar uma crítica da representação, o que não implica retirar da imagem sua dimensão política; mas, em sentido contrário, significa afiar seu gume. É interessante pensar que do ponto de vista da dramaturgia, a imagem-individuação pode constituir-se como campo de forças entre signos - entre o signo corporal e o signo de luz, - em função das "variações de longitude, ou seja, de relações complexas de velocidades e retardamentos", ou "variações de latitude, entendida como alterações de potência, do poder de afetar ou de ser afetado", ainda nos termos de Deleuze (1997).

A dramaturgia visual, assim concebida, não ficaria circunscrita ao campo da composição no sentido clássico de "unidade na multiplicidade" (ou, seja, de hipotaxe, enquanto hierarquização de elementos), ou ainda como construção, no sentido moderno de justaposição de partes (ou seja, de parataxe, enquanto série de elementos permutáveis, como em certas "montagens" de Samuel Beckett ou Robert Wilson), porque nestes casos estaríamos ainda no âmbito da relação entre a parte e o todo. Não se poderia, também nessa dramaturgia, pressupor a noção de autoria (ou do dramaturgo como demiurgo), fundada em uma filosofia do sujeito, haja vista que essa dramaturgia de imagens-individuação consistiria de "relações de forças materiais e transitórias"; que não assumem nenhuma unidade, nem iden- 
tidade estável (Sauvagnargues, 2006, p. 163). Ou seja: a "imagem-individuação corpo-luz", aqui entrevista (como em certas videoinstalações), constituir-se-ia enquanto "zona de indeterminação" ou de passagens entre signos, de um ao outro e de um em outro, no interior de um campo de forças, tais como as efetuadas, pelo "diagrama" em pintura (em "Francis Bacon, lógica da sensação", de 1981) ou pelos "personagens conceituais" em literatura (em "Crítica de clínica", de 1993); ou, evidentemente, na "imagem-movimento no cinema" resultante das passagens entre "imagem-percepção", "imagem-ação" e "imagem-afecção" (em Cinema 1: imagem movimento, de 1983).

É possível figurar também o tempo no teatro como campo expandido a partir das considerações de Deleuze sobre a imagem cinematográfica. A passagem de uma imagem a outra, à qual nos referíamos, pode ser pensada neste teatro-cinema, de modo análogo à passagem entre "imagem-movimento" que permite uma "representação indireta do tempo", ou seja, que subordina o tempo (associada ao cinema clássico, por Deleuze), e a "imagem-tempo" (associada ao cinema moderno) que possibilita uma "apresentação direta do tempo", de um "tempo puro liberado do movimento" (Deleuze, 1990). Neste teatro seria assim possível modular o tempo segundo sua latitude e longitude, como vimos, tendo em vista, as variações de velocidade ou de potência das imagens, respectivamente. Sem abdicar da representação indireta do tempo, mas tomando-a tão somente como uma das ideias concebíveis de tempo, poder-se-ia, em suma, pensar o tempo na imagem a partir da ideia de "feixe de temporalidades", haja vista que não se trataria, aqui, de "uma linha do tempo, nem de um círculo do tempo, ou tampouco de uma flecha invertida, ou quebrada, mas de uma rede que implica navegação multitemporal em fluxo aberto - o tempo como uma rede de fluxos intercruzados" (Pelbart, 2000, p. 191). Cada obra posta em cena, nessa dramaturgia visual, aqui encenada, criaria, em síntese, uma "figura singular de tempo" (idem).

Esse teatro como forma compósita, porque mix-de-midias, incorporadas à estrutura da encenação constituiria, assim, uma "paisagem ótica", na expressão de Lehmann, marcada por "trocas reais" entre "corpo vivo" e "técnica digital", ou, nos termos de Mil Platôs de Deleuze, entre o "universo cine-maquínico" e o "corpo subjetivado das imagens" (Lehmann, 2011; Deleuze, 1997). Nessa situação de "co-presença" teríamos, segundo Lehmann, um jogo entre a "presença do vídeo" 
e a "presença ao vivo do corpo do ator"; ou seja, "um jogo como experiência de conflito entre corpo presente e manifestação imaterial de uma imagem dentro de uma mesma encenação" (Lehmann, 2011, p. 382). Nessa hipótese, o ator seria uma "perturbação da imagem eletrônica" e vice-versa (idem, p. 383). Essa relação entre a "imagem de vídeo" ("imaterial") e "ator-vivo" ("corpo presente"), considerada por Lehmann, como conflituosa ou perturbadora do regime de imagens, pode também operar, vale notar, como fecundação recíproca entre diferentes formas de percepção; ou, entre níveis ontológicos de imagem. ${ }^{3}$

Do uso das mídias eletrônicas como endosso da representação, sem que haja sua efetiva incorporação à estrutura da encenação, pode resultar, como alertávamos, um teatro como documento, ou seja, de mera comunicação imediata. Entenda-se, aqui, por documento algo diretamente referenciado na dita realidade existente, de modo que em um "teatro documental" não haveria uma reconfiguração da realidade material na imanência da forma teatral, ou seja, enquanto imagem-individuação. Como mostrou Hal Foster, desde o fim dos anos 1990 tem havido um retorno progressivo ao "referente", com a substituição do sujeito definido em termos de relações econômicas, para um sujeito definido em termos de identidade cultural. É a noção do dramaturgo como etnógrafo, que permitiria, neste caso, compreender a tendência atual de "retorno do real" (Foster, 2014, p. 167). O dramaturgo, assumindo a posição de "mecenato ideológico", acabaria por reduzir as obras a "informes etnográficos", como teria ocorrido, segundo certos críticos em diversos trabaIhos, sobretudo vídeos apresentados na $31^{a}$. Bienal de São Paulo: "Como (...) de coisas que não existem", em 2014. Seria o risco da "autoalterização", ou seja, do dramaturgo "tomar o outro ser como fantasia primitivista", em uma "idealização" segundo a qual haveria "algo puro, sem mediação", e, no limite, insondável; ou, em sentido contrário, que seria possível um "acesso pleno ao outro", assumindo-

\footnotetext{
${ }^{3}$ Em Archive (Avignon, 2014) (Arquivo), peça apresentada na Mostra Internacional de São Paulo (MITsp), em 2015, o performer israelense Arkadi Zaides cria uma coreografia, em cena, a partir de imagens de vídeo exibidas simultaneamente à sua atuação corporal. São imagens tecnicamente precárias, antiespetaculares, produzidas em 2007 por palestinos que habitavam um território ocupado ilegalmente por colonos e militares de Israel. Nesta performance, na qual o público ocupa, no espaço da sala de exibição, a posição dos videomakers palestinos, há um jogo complexo de visibilidades. Há uma "perturbação" da percepção do observador, como quer Lehmann, tendo em vista que a atenção é levada a se deslocar, reiteradamente, do "corpo vivo" do performer no presente, à imagem de vídeo que registra uma ação no passado. Acrescente-se a esse deslocamento inquietante, a incorporação pelo performer da gestualidade das personagens apresentadas no vídeo, de tal sorte que ele se faz, no curso da peça, arquivo vivo: gesta de gestos.
} 
se, nesta hipótese, um "pressuposto realista" - o que permitiria, por essa via, atar estética e política. (Foster, 2014, p. 167). Foster afirma, rejeitando esses pressupostos, que a "reflexividade", ou a "distância crítica", é condição necessária para proteger o artista dessa "superidentificação com o outro", que, no extremo, acabaria por comprometer até mesmo a "condição de outro" (idem, p. 194). Afastando-se, assim, de obras que visam à representação direta de uma dada realidade social ou política (o dito referente) o autor postula "a obra enquanto paralaxe, que procura "enquadrar o enquadrador, enquanto este enquadra o outro"; ou, ainda, aproximando-se de Jacques Lacan, afirma que a arte deve figurar a experiência individual e histórica enquanto "trauma", ou seja, como "encontro falido com o real" entendendo este último termo como aquilo que é impossível de ser representado, mas que deve ser suposto para manter sua consistência (Foster, 2014, p. 167). Desse modo, no teatro expandido - acolhendo-se as advertências de Foster - não teríamos um teatro da "comunicação imediata", ou um "documento etnográfico", como ocorre com grupos da cena teatral contemporânea, que, no intento de politizar a estética, representam sem mediações a realidade social e política; mas, um teatro da "comunicação... sem comunicação", o qual, pelo "efeito de matéria", aludiria ao "inapresentável", na expressão de Jean-François Lyotard (1993, p. 93), ou ao "real", na leitura de Foster (2014).

Este teatro da dramaturgia visual pode sucumbir também, à espetacularização das imagens, ao "discurso hiperbólico das mídias", na expressão de Lehmann: "Se os gestos de interrupção reflexiva são considerados dispensáveis face ao registro sem demora das informações, a perspicácia versada tecnologicamente ameaça se converter em ideologia, na apoteose do funcionamento cego" (Lehmann, 2007, p. 402). Em outras palavras, é preciso diferenciar um "uso (tecnológico) meramente decorativo, ilustrativo, utilitário, digestivo, pirotécnico e de eletroentretenimento, de uma efetuação que tenta criar honestamente uma experiência estética" (Campos, 1993). Sendo assim, não se deve fetichizar os novos meios tecnológicos, "mas produzir um jogo com a percepção", "que permita a experiência concreta por parte do público de que sua fascinação se prende à imagem do monitor" (Lehmann, 2007, p. 402). Este teatro com mídias, que "não prescinde na maioria das vezes, do contato visual direto entre atores e público", seria, assim, um espaço de "autoconsciência por parte do público de sua convivência ou, como diziam Hélio 
Oiticica e Neville D'almeida, a propósito de Quase-Cinema: Block-Experiments, Cosmococas, de 1973, de "sua coni-convivência" com "as estruturas tecnológicas", cada vez mais presentes (Favaretto, 1992). ${ }^{4}$

Furtando-se à teatralização das mídias, evitar-se-ia a fruição como fascínio pelas imagens eletrônicas, tomando-se, aqui, o termo fascínio por uma "paixão niilista pelos modos de desaparição do real", no sentido de Jean Baudrillard: "Estamos fascinados por todas as formas de desaparecimento, do nosso próprio desaparecimento; melancólicos e fascinados" - ou, ainda, "eufóricos e disfóricos", agora nos termos de Gilles Lipovetsky (2004, p. 63), - "esta é a nossa situação geral na era da transparência involuntária", no interior da "sociedade da hipervisibilidade" (Baudrillard, 1991, p. 62). Esse fascínio, denominado também por Baudrillard de "sedução psicológica e operacional", ou ainda, de "sedução dos jogos multimidiáticos", nada teria de "erotismo", de "sedução-desafio, mítica, dual e antagônica" (idem). Nessa "sociedade da hiperrealidade", na qual as imagens são percebidas como mais reais que o "real", viver-se-ia a "morte lenta", "comatosa" do "real" (aqui entendido como erfahrung, ou experiência individual e coletiva), "sem a possibilidade de um redentor suspiro" (Baudrillard, 1986, p. 90).

Reagindo a este estado de luto pela "morte do real", o "teatro expandido", assim como certas videoinstalações de Nan June Paik, de Bill Viola, de Gary Hill, ou de Wilhelm Kentridge, constituiria uma "plataforma laboratorial", na expressão de Nicolas Bourriaud, na qual se problematizaria o destino da imagem na contemporaneidade. É preciso promover, na sala de teatro assim como nas videoinstalações no circuito de artes visuais, uma arqueologia do olhar, para que a imagem recue ao momento de sua própria constituição. É necessário recuar às origens da visão, à noite que antecede ao surgimento das formas; tendo em vista que as "trevas são uma pré-imagem" indispensável na "ordem das coisas visíveis", na visão do

\footnotetext{
${ }^{4}$ Nem sempre, contudo, há coexistência tensa entre imagens eletrônicas e signos corporais. Em Stfiters dinge (Coisas de Stifter), obra de 2017 do diretor e compositor alemão Heiner Goebbels, também apresentado na Mostra Internacional de São Paulo (MITsp), em 2015, temos uma "instalação" de instrumentos musicais e elementos cenográficos. Neste "teatro da ausência", porque sem atores, que encena o aparato visual e sonoro (som, luz, água, névoa etc.), aproximando-se assim das artes visuais (como de "instalações sonoras"), a única presença corporal é a do público (ou de contrarregras). Mesmo supondo que o intento deste "concerto cênico", ou "espetáculo-instalação" que exibe engrenagens, como se essas operassem por si mesmas, seja criticar em chave distópica a realidade existente, há que se considerar a ameaça do virtuosismo técnico, endossar, também aqui, malgrado o intento do diretor, essa mesma realidade.
} 
fotógrafo cego Evgen Bavchar (1992, p. 30). A escuridão, aludida por Bavchar, que atribui uma efetuação à luz distinta da luz midiática (da imagem analógica ou numérica da mas-cult ou da rede digital), opõe-se à hipervisão da sociedade de consumo. A luz se apresentaria, aqui, como a negatividade que antecipa a imagem. Seria assim no espaço penumbroso de uma videoinstalação, ou na câmara escura de um teatro-cinema, na qual o corpo do ator interage com a imagem de luz, que poderia reluzir - a julgar pelas obras desses artistas - a uma imagem in status nascendi, ainda não corroída pela exposição exagerada: outra imagem.

Dito de outro modo: esta situação de copresença entre o corpo do ator e imagem eletrônica poderia, opondo-se ao cliché que nada esconde revelar "o rosto afastado da ausência": "o espaço off que se apresenta como excluído" (Dubois, 1994, p. 169). Os pólens de luz, o suporte da imagem eletrônica, produziriam, neste caso - segundo Philippe Dubois (1994, p. 325): "uma imagem flutuante, adiada", uma "presença muda", um "tumulto silencioso" que "impregnaria" o imaginário do observador. Esse lusco-fusco (como um "Fort-Da" de luz arisca) restituir-Ihe-ia o poder de interpretação, "o mergulho interior, penetração na profundidade das significações e dos afetos", no sentido da "captura de forças insensíveis em novos materiais", como quer Deleuze (Sauvagnargues, 2006, p. 162). É preciso, alertava Lyotard por sua vez, na verificação da potência da imagem tecnológica, que se proceda a "uma análise fenomenológica da presença do virtual" (Lyotard, 1998, p. 118), assim como, de modo análogo, Lehmann afirma, referindo-se às mídias mescladas no teatro pós-dramático, a necessidade de "outra versão do virtual" (Lehmann, 2007, p. 387). "É possível - perguntava Lyotard (1988, p. 101) - atingir o "pathos" pela imagem eletrônica? Será que "pode ocorrer algo" (um "sentimento de gozo" ou de "pertencimento" decorrente da "comunicabilidade imediata" entre a obra e o observador) por meio de um computador? (Lyoyard, 1997, p. 258); ou será que a "imagem videográfica" (analógica ou digital) anula a facticidade dos eventos impossibilitando uma "recepção carnal", ou seja, uma fruição "pelo homem, no tempo, em um lugar", nos termos de Lehmann (2007, p. 414). Diversos autores não acreditam, todavia, que as possibilidades abertas pelas novas mídias permitirão ao observador "aceder ao pathos", na expressão citada de Lyotard, ou alçar os novos meios técnicos "ao novo universo estético do sublime tecnológico", no sentido de Mário Costa (1995, p. 22), como atesta o grande número de "ima- 
gens numéricas ocas", "imagens sem presença", que nada representam além do vazio (Maciel, 1997, p. 253). Percebendo essas imagens, segundo Lyotard, só resta dizer, tão somente: "Não há apresentação coisa alguma está aqui, agora; só há inocorrências e não acontece mais nada" (Lyotard, 1997, p. 253).

Tomemos as videoinstalações cênicas de Wilhelm Kentridge, apresentadas tanto no circuito das artes visuais quanto teatral, baseadas em tecnologias obsoletas de filmes de animação, desenhados quadro a quadro. Esta animação da "idade da lanterna mágica", na caracterização do próprio artista (dramaturgo; cine-animador e coreógrafo) operaria como uma forma de resistência aos filmes softwares norte-americanos que reduziram a alta tecnologia à produção de efeitos pirotécnicos. Nessas animações artesanais, inspiradas em antigos teatros de marionetes, figuras em silhueta saltitam, trepidam, em função do artesanato na fatura, incitando o observador a preencher as fraturas, suprindo as imagens (supostamente) ausentes. É o que ocorre, por exemplo, em seu filme de animação Procissão de sombras, de 1999, na qual o artista "encena" a transição da apartheid para a "democracia", recorrendo ao teatro de sombras, produzido a partir de marionetes, característico da cultura popular da África do Sul. Neste vídeo, editado segundo princípios de montagem vanguardista, Kentridge volta-se à relação entre corpos e sombras, ou seja, à questão acima referida da origem das imagens em contexto multimídia tendo em vista que a animação é projetada em uma instalação composta por diversos materiais: "A própria tenuidade da ilusão (em função da trepidação e dos borrados das silhuetas), diz o artista encenador, impele-nos a completar o reconhecimento, e isso nos instiga à própria consciência da atividade em si - a reconhecer nesta atividade a nossa ação ao apreender o mundo" (Kentridge apud Huyssen, 2014, p. 62). De modo semelhante, autores como Philippe Dubois ou Raymond Bellour (1997), ao investigarem os rumos da imagem na contemporaneidade, têm atribuído à "estética da imperfeição", uma forma de recusa à neutralização da imagem no presente. De fato, reagindo à imagem pregnante (HD, ou virtual), alguns artistas, na direção de Kentridge, encontraram na imagem floue, de cores esmaecidas, de contornos esbatidos, ou ainda em imagens gauches - dubitativas, amadorísticas, desglamorizadas, intencionalmente apressadas - , a possibilidade de se devolver à imagem o seu enigma e, ao observador, o imprevisto.

Este teatro como campo expandido seria, em suma, o lugar, por excelência para o 
desenvolvimento do drama da percepção na contemporaneidade. A questão, referida neste texto a certa prática teatral, está no centro da reflexão estética atual. $\mathrm{Na}$ confluência das linguagens, de signos de luz e do corpo do ator, teríamos a possibilidade de uma crítica às imagens circulantes, em busca de uma imagem-crítica, de uma "imagem dialética", diria Walter Benjamin (1984). Podemos conceber esse teatro, aqui dramatizado, como uma agonística, como um lugar e momento decisivos nos quais se desenvolveria uma luta relativa ao destino da imagem. Em Beleza exorbitante, Jean Galard mostra que foi com o "abuso estético" que percebemos que a "beleza difícil" "era tão mortal" (Galard, 2012, p. 73). Seria a "imagem escrupulosa", a que pode "suscitar um olhar apreensivo, com um pouco de ansiedade, ou mesmo de temor", que reagiria à "beleza exagerada" (idem, p. 59). Na "beleza alusiva", avessa a beleza imperativa, a que oculta algo, que atrai não pelo que mostra mas pelo que só indicia, residiria o poder redibitório da imagem: o de devolver ao olho a possibilidade de ver. Daí o caráter laboratorial, senão heterotópico, desse teatro intermídia, que permite entrever, no devir da imagem, alternativas à realidade existente.

Nesse sentido, é que "a política do teatro é uma política da percepção realizada no modelo reduzido da situação teatral" - na ótica de Lehmann (2007, p. 388) -, "porque ela faz da natureza da própria visão o objeto de uma percepção consciente: visão da visão". Esta agonística da imagem é mencionada, também, nos textos sobre cinema de Deleuze, porque esses questionam o estatuto da imagem no interior da sociedade do espetáculo. Seria no "cinema autorreflexivo", como o de Jean-Luc Godard, e não no "cinema reflexivo", como o de Ingmar Bergman segundo Deleuze -, que se travaria o drama da percepção. Pois, "em vez de se ater a uma consciência crítica negativa (como o cinema de denúncia política, baseado na representação direta de um objeto), ou apenas paródica, o cinema mais relevante" - ainda segundo Deleuze - "engajou-se em sua mais elevada reflexão, e não parou de aprofundá-la e de desenvolvê-la"; de tal maneira, que teríamos, por exemplo, "em Godard, fórmulas que exprimiriam o seguinte problema: se as imagens tornaram-se clichês tanto no interior quanto no exterior, como extrair de todos esses clichês uma Imagem, justo uma imagem"? (Retomando, aqui, a frase célebre de Godard: "Não é uma imagem justa, é justo uma Imagem") (Deleuze, 1985, p. 263). "Do conjunto desses clichês" - conclui Deleuze, Cinema 1, a ima- 
gem-movimento" (1985) - "deve sair uma imagem": "Com que política e com que consequências? Afinal o que é uma imagem que não seria um clichê? Onde acaba o clichê e começa a imagem? " (Uma imagem-individuação que se entremostra como sendo a "mais difícil", diz Deleuze) (idem, p. 263). O problema do espectador torna-se, então, "o que há para se ver na imagem"? E não mais: "o que veremos na próxima imagem" (idem, p. 264).

De modo semelhante, Lehmann afirma que "a imagem eletrônica carece de uma falta, e por isso meramente conduz até a próxima imagem, na qual mais uma vez nada perturba", haja vista que a civilização das imagens é uma sucessão infinita de imagens - a "tela-total", na expressão já exibida de Baudrillard. Retomando a questão, proposta há pouco: "como esperar que do conjunto dos clichês (entendidos, aqui, como imagem-representação ou imagem-simulacro) saia uma imagem (uma 'imagem-individuação') "? Para tanto, é preciso no teatro como comunidade das artes que as linguagens do teatro, do cinema ou vídeo, sejam levadas de tal modo ao seu limite de força e intensidade, que de seu entrecruzamento resulte uma "beleza difícil", como quer Galard; uma imagem na qual alguma coisa venha de fora, algo que "force o pensamento", no sentido de Deleuze; algo como o "chegante", diria Derrida (2003, p. 78); algo que "aconteça no acontecimento", diria Lyotard (1987); algo como o "impensado", afirmaria Foucault (1981); "uma possibilidade indefinida", resumiria Lehmann (2007); algo, por fim, como o "isso", no sentido psicanalítico de pulsão, de inconsciente, de outro do sentido; algo que rompa, enfim, com o horizonte do provável, que interrompa toda organização performativa, toda convenção ou todo contexto dominável por um convencionalismo. Somente, assim, na subtração de elementos de poder, se liberará, nesta dramaturgia visual, uma força não representativa, como potência da imagem. 


\section{Referências}

BAUDRILLARD, Jean. Simulacros e simulação. Lisboa: Relógio d'Água, 1991.

BAUDRILLARD, Jean. Da sedução. Campinas: Papirus, 1991.

BAUDRILLARD, Jean. Tela total, mito-ironias da era do virtual e da imagem. Porto Alegre: Sukina, 2005.

BAVCHAR, Evgen. Le vouyeur absolu. Paris: Seuil, 1992.

BELLOUR, Raymond. Entre-imagens. Campinas: Papirus, 1997.

BENJAMIN, Walter. Obras escolhidas: magia e técnica, arte e política. São Paulo: Brasiliense, 1986.

BENJAMIN, Walter. Origem do drama barroco alemão. São Paulo: Brasiliense, 1984.

BOURRIAUD, Nicolas. Estética relacional. São Paulo: Martins Fontes, 2009.

BOURRIAUD, Nicolas. Radicante: por uma estética da globalização. São Paulo: Martins Fontes, 2011.

BOURRIAUD, Nicolas. Formas de vida: a arte moderna e a invenção de si. São Paulo: Martins Fontes, 2011 a.

BRETT, Guy. Brasil experimental: arte/vida: proposições e paradoxos. Rio de Janeiro: Contra Capa, 2005.

CAMPOS, Augusto. Do ideograma ao videograma. Folha de São Paulo.São Paulo, 16 maio 1993.

CLARK, Lygia. In: DISERENS, Corinne; TODOLI, Vicente; COESENS, Piet (Orgs.). Lygia Clark. Barcelona: Fundació Antoni Tápies: MAC,1998.

COSTA, Mario. O sublime tecnológico. São Paulo: Experimento, 1995.

DELEUZE, Gilles. Sobre o teatro: um manifesto a menos. Rio de Janeiro: Jorge Zahar Editores, 2010.

DELEUZE, Gilles. Proust e os signos. Rio de Janeiro: Forense Universitária, 2010a.

DELEUZE, Gilles, GUATTARI, Félix. Mil platôs: capitalismo e esquizofrenia. Rio de Janeiro: Editora 34, 1995-1997. v. 5.

DELEUZE, Gilles. Diferença e repetição. Rio de Janeiro: Graal, 1988.

DELEUZE, Gilles. Cinema 1: a imagem-movimento. São Paulo: Brasiliense, 1985. 
DELEUZE, Gilles. Cinema 2: a imagem-tempo. São Paulo: Brasiliense, 1990.

DELEUZE, Gilles. Crítica e clínica. São Paulo: Editora 34, 1997.

DELEUZE, Gilles. Francis Bacon: lógica da sensação. Rio de Janeiro: Jorge Zahar, 2007.

DERRIDA, Jacques. A universidade sem condição. São Paulo: Estação Liberdade, 2003.

DUBOIS, Philippe. O ato fotográfico e outros ensaios. Campinas, Papirus, 1994.

FAVARETTO, Celso F. A invenção de Hélio Oiticica. São Paulo: Editora da Universidade de São Paulo, 1992.

FOUCAULT, Michel. As palavras e as coisas: uma arqueologia das ciências humanas. São Paulo: Martins Fontes, 1981.

FOSTER, Hal. O retorno do real. São Paulo, Cosac Naify, 2014.

GALARD, Jean. Beleza exorbitante: reflexões sobre o abuso estético. São Paulo: Editora Fap-Unifesp, 2012.

HUYSSEN, A. Culturas do passado-presente: modernismos, artes visuais, políticas da memória. São Paulo: Contraponto, 2014.

LACAN, Jacques. O seminário, livro 11 , os quatro conceitos fundamentais da psicanálise. Rio de Janeiro: Jorge Zahar, 1996.

LEHMANN, Hans-Thies. O teatro pós-dramático. São Paulo: Cosac Naify, 2007.

LIPOVETSKY, Gilles. Os tempos hipermodernos. São Paulo: Barcarolla, 2004.

LYOTARD, Jean-François. O inumano: considerações sobre o tempo. Lisboa: Editorial Estampa, 1990.

LYOTARD, Jean-François. Algo assim como: comunicação sem comunicação. In: PARENTE, André. (Org.). Imagem Máquina: a era das tecnologias do virtual. Rio de Janeiro: Editora 34, 1993.

LYOTARD, Jean-François. Que Peindre?: Adami, Arakawa e Buren. Paris: Éditions de la Différence, 1987.

MACIEL, Katia. A última imagem. In: PARENTE, André (Org.). Imagem máquina: a era das tecnologias do virtual. Rio de Janeiro: Editora 34, 1993.

MONDRIAN, Piet. Neoplasticismo na pintura e na arquitetura. São Paulo: Cosac Naify, 2008. 
PELBART, Peter Pal. A vertigem por um fio: políticas da subjetividade contemporânea. São Paulo: Iluminuras/Fapesp, 2000.

RANCIÈRE, Jacques. O espectador emancipado. São Paulo: Martins Fontes, 2012.

SAUVAgnARgueS, Anne. Deleuze et I'art. Paris: Presses Universitaires France, 2006.

SAUVAGNARGUES, Anne. L'éthologie: I'affect de I'image. In: __ Symposium: Canadian Journal of Continental Philosophy, v. 10, n. 1, p. 155-167, 2006.

SAUVAGNARGUES, Anne. Écologie des images et machine d'art. In: Pourpalers Deleuze: Entre art et philosophie. Reims: Épure: Éditions et Presses Universitaire de Reims, 2013.

SCHILLER, Friedrich. A educação estética do homem: numa série de cartas. São Paulo: Iluminuras, 1990. 